\title{
Surveillance of Pediatric Cardiac Surgical Outcome Using Risk Stratifications at a Tertiary Care Center in Thailand
}

\author{
Chodchanok Vijarnsorn, ${ }^{1}$ Duangmanee Laohaprasitiporn, ${ }^{1}$ Kritvikrom Durongpisitkul, ${ }^{1}$ \\ Prakul Chantong, ${ }^{1}$ Jarupim Soongswang, ${ }^{1}$ Paweena Cheungsomprasong, ${ }^{1}$ \\ Apichart Nana, ${ }^{1}$ Somchai Sriyoschati, ${ }^{2}$ Thawon Subtaweesin, ${ }^{2}$ Punnarerk Thongcharoen, ${ }^{2}$ \\ Ungkab Prakanrattana, ${ }^{3}$ Jiraporn Krobprachya, ${ }^{4}$ and Julaporn Pooliam ${ }^{5}$ \\ ${ }^{1}$ Division of Pediatric Cardiology, Department of Pediatrics, Faculty of Medicine Siriraj Hospital, Mahidol University, \\ Bangkok 10700, Thailand \\ ${ }^{2}$ Division of Cardio Vascular Thoracic Surgery, Department of Surgery, Faculty of Medicine Siriraj Hospital, Mahidol University, \\ Bangkok 10700, Thailand \\ ${ }^{3}$ Department of Anesthesiology, Faculty of Medicine Siriraj Hospital, Mahidol University, Bangkok 10700, Thailand \\ ${ }^{4}$ Department of Pediatrics, Faculty of Medicine Siriraj Hospital, Mahidol University, Bangkok 10700, Thailand \\ ${ }^{5}$ Office for Research and Development, Faculty of Medicine Siriraj Hospital, Mahidol University, Bangkok 10700, Thailand
}

Correspondence should be addressed to Chodchanok Vijarnsorn, cvijarnsorn@yahoo.com

Received 22 October 2010; Revised 5 January 2011; Accepted 12 February 2011

Academic Editor: Jeffrey P. Jacobs

Copyright (c) 2011 Chodchanok Vijarnsorn et al. This is an open access article distributed under the Creative Commons Attribution License, which permits unrestricted use, distribution, and reproduction in any medium, provided the original work is properly cited.

\begin{abstract}
Objectives. To determine in-hospital mortality and complications of cardiac surgery in pediatric patients and identify predictors of hospital mortality. Methods. Records of pediatric patients who had undergone cardiac surgery in 2005 were reviewed retrospectively. The risk adjustment for congenital heart surgery (RACHS-1) method, the Aristotle basic complexity score (ABC score), and the Society of Thoracic Surgeons and the European Association for Cardiothoracic Surgery Mortality score (STSEACTS score) were used as measures. Potential predictors were analyzed by risk analysis. Results. 230 pediatric patients had undergone congenital cardiac surgery. Overall, the mortality discharge was $6.1 \%$. From the ROC curve of the RACHS-1, the ABC level, and the STS-EACTS categories, the validities were determined to be $0.78,0.74$, and 0.67 , respectively. Mortality risks were found at the high complexity levels of the three tools, bypass time $>85 \mathrm{~min}$, and cross clamp time $>60$ min. Common morbidities were postoperative pyrexia, bleeding, and pleural effusion. Conclusions. Overall mortality and morbidities were 6.1\%. The RACHS1 method, ABC score, and STS-EACTS score were helpful for risk stratification.
\end{abstract}

\section{Introduction}

During the past two decades, dramatic improvements have been seen in both diagnostic tools and treatments for heart diseases in pediatric patients. Advances in neonatal surgery, interventional cardiac catheterization, cardiac anesthesia and intensive care, cardiopulmonary bypass systems, and mechanical assisted device have been key achievements in outcomes, especially in the critical patients. The in-hospital mortality rates for pediatric cardiac surgery decreased significantly from $8.7-22 \%$ to $4.6-6 \%$ in the past two decades
[1-5]. Recently, a report on indigenous Australian pediatric patients who had undergone congenital cardiac surgery showed overall complication rates of $20-32 \%$ and a mortality rate of $1.82 \%$. The major postoperative complications were conduction disturbance (17\%), valve dysfunction (6\%), and tamponade (3\%) [1]. In addition, a mortality outcome of up to $0.62 \%$ occurred within 365 days after hospital discharge. Chang et al. [6] indicated that the important risk factors of posthospital discharge death were young age and type of surgery. Silka et al. [7] reported that the majority of these patients had diagnoses of aortic stenosis, coarctation of aorta, 
transposition of great arteries, and tetralogy of Fallot. The major causes of death were cardiac arrhythmia, aneurysmal rupture, and heart failure.

To measure the performance of surgical outcome has been difficult because of the relative low number and heterogeneity of patients and the diversity of operations [8-10]. The risk adjustment for congenital heart surgery (RACHS-1) method can be used to stratify individual patients into six categories, based on type of surgery and age at operation, for predicting hospital mortality [11-13]. Another well-known tool is the Aristotle basic complexity score (ABC score) which allocates the complexity scores on the basis of the primary procedure (ranging from 1.5-15) and complexity levels (1-4) $[14,15]$. The newest model, developed from the empiricalbased analysis from the European Association for Cardiothoracic Surgery (EACTS) congenital heart surgery database and the Society of Thoracic Surgeons (STS) congenital heart Surgery database, is the STS-EACTS mortality score and categories [16]. The large, recent study of 77,294 registered procedures showed a high degree of discrimination for predicting mortality, using these three tools and $\mathrm{c}$ statistic $(0.74-0.78)[16,17]$.

In Thailand, pediatric cardiac surgery and postoperative care have been developing gradually since 1970 . Fundamentally, each institute assesses clinical outcomes based on their observational databases. As a result, an overall performance assessment has been lacking, especially for the whole country. Currently, administrative databases are being constructed using the ICD-9-CM code. Siriraj Hospital, which is a university hospital and a tertiary cardiac center, is one of the main referral hospitals in Thailand for congenital cardiac surgery and intervention. Congenital cardiac surgery at Siriraj Hospital involves 300-400 cases per year, with up to $70 \%$ being in the pediatric age group. Not only accurate data is needed for pediatric cardiac surgery outcomes, to measure institutional performance, but also preliminary survey results are needed for a national database. The final goal is to improve the quality of care and achieve world standards. This preliminary surveillance project has two main objectives: (1) to characterize the epidemiology of contemporary outcomes, including in-hospital mortality rates and complications among pediatric patients who have undergone cardiac surgery at Siriraj Hospital, using the RACHS-1, ABC level, and STS-EACTS Mortality Categories and (2) to perform a risk factor analysis of hospital mortality.

\section{Materials and Methods}

2.1. Data Sources. The present study was designed as a retrospective descriptive study and approved by the Siriraj Institutional Review Board and Ethics Committee. All pediatric patients (ages ranging from 0 to 15 years old, excluding preterm babies who underwent cardiac surgery between January 1 and December 31, 2005) were identified using the Siriraj Hospital Cardiothoracic Division database. Demographic data was reviewed for: age at the first presentation at the hospital, gender, age at the onset of symptom presentation, presence of genetic syndrome, and diagnosis of congenital heart disease. The preoperative and intraoperative data included type of operation, cardiopulmonary bypass time (CPB time), and aortic cross clamp time (AoX time). The postoperative data included outcomes like in-hospital morbidities and mortalities, which were categorized by the RACHS-1 method, ABC level, and STS-EACTS mortality categories $[11,12,14,16,17]$. Retrospective variables were identified, and a statistical analysis was performed on the effects of preoperative and intraoperative factors on surgical outcomes.

2.2. Study Variables. Postoperative death before hospital discharge was used as the main outcome variable. For secondary outcome variables, postoperative morbidities were considered. These included cardiac arrest, reoperation, postoperative reintubation, low cardiac output, acute renal failure requiring peritoneal dialysis, pyrexia ( $>38$ degrees Celsius), pleural effusion, and serious cardiac arrhythmia such as complete AV block, junctional ectopic tachycardia, supraventricular tachycardia, atrial ectopic tachycardia, ventricular tachycardia, and ventricular fibrillation requiring medical or electrical cardioversion.

2.3. Data Analysis. Patients' baseline characteristics and potential confounders were summarized using descriptive statistics (showing the percentage, median, and range). The ROC curve was examined for validation of the RACHS1 level, ABC level, and STS-EACTS Mortality categories. Associations between potential risk factors and poor outcomes were assessed with univariate analysis. Continuous variables were assessed with a Mann-Whitney $U$ test, and the categorical variables were evaluated by a Fisher's exact test or a chi-square test. Multivariate analysis was performed with forward stepwise logistic regression, combined for each outcome. A $P$ value $<.05$ was considered to be statistically significant. Statistical analysis was performed with SPSS 10.0 for Windows (SPSS Inc., Chicago, IL, USA).

\section{Results}

3.1. Demographic Data. During the 12-month study period, a total of 411 congenital cardiac surgical procedures were performed on patients at Siriraj Hospital. Of these, 230 cases met the eligibility criteria (Figure 1). Demographic data of the patients are shown in Table 1 .

3.2. Surgical Procedures. The majority of procedures were open-heart surgery $(82.6 \% ; n=190)$. The most frequent procedure was ventricular septal defect patch closure (30.4\%), followed by tetralogy of Fallot repair (16.1\%) and systemic-to-pulmonary shunt (11.8\%) (see Table 2). Average cardiopulmonary bypass time and average aortic cross clamp time were $84.9 \pm 66.8$, and $42.5 \pm 34.7$ minutes, respectively. Most of the procedures were stratified into the RACHS-1 levels of 1 and 2 (60.9\%), ABC levels of 1 and $2(56.1 \%)$, and STS-EACTS mortality categories of 1 and 2 (66.9\%). Overall, the mean Aristotle basic score was $7.1 \pm 1.9$. The mean STSEACTS mortality score was $0.65 \pm 0.54$ (see Table 3 ). 


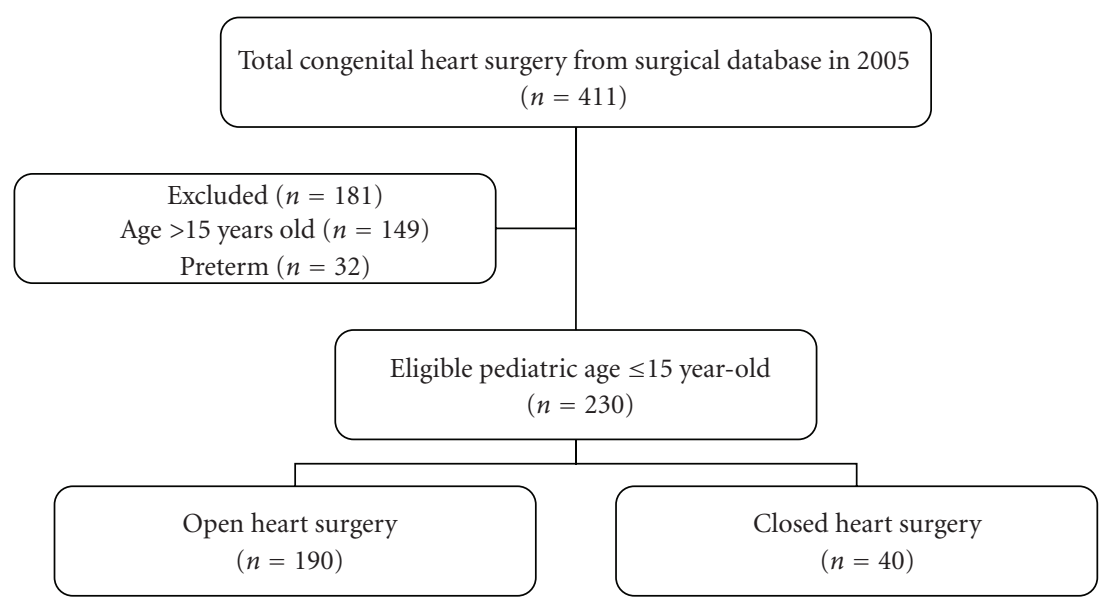

FIgURE 1: Flow chart of participants through the study.

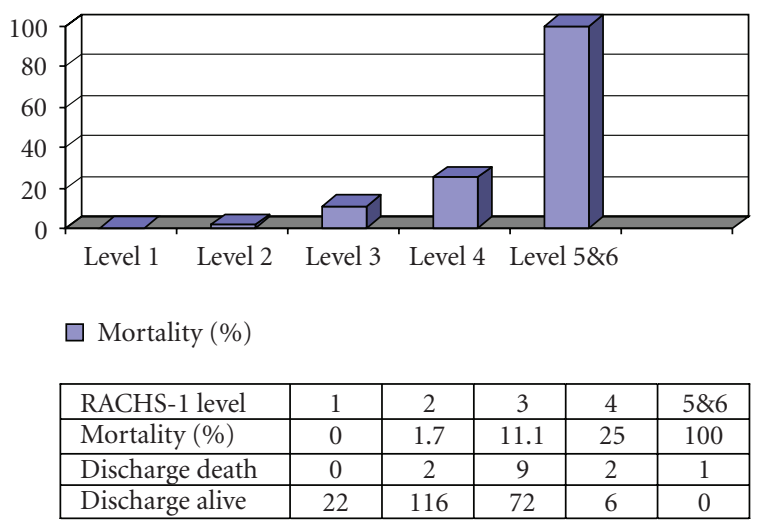

FIgUre 2: Mortality rate by RACHS-1 in the present study $(n=230)$.

TABle 1: Patients' baseline characteristics in the present study $(n=230)$.

\begin{tabular}{lc}
\hline Characteristics & $\begin{array}{c}n(\%) \text { or } \\
\text { median } \\
\text { (range) }\end{array}$ \\
\hline Sex; $n(\%)$ & $126(54.8)$ \\
$\quad$ Male & $104(45.2)$ \\
$\quad$ Female & $0.6(0-14.5)$ \\
Age at presentation (years); median & \\
(range) & $4.3(0.02-15)$ \\
Age at surgery (years); median (range) & $5(2.7)$ \\
$\quad<30$ days; $n$ (\%) & $53(23.4)$ \\
$\quad 31$ days to 1 year; $n(\%)$ & $172(73.9)$ \\
$\quad 1$ year; $n$ (\%) & $7(3.0)$ \\
Definite genetic syndrome; $n(\%)$ & 6 \\
$\quad$ Down syndrome & 1 \\
$\quad$ VATER association &
\end{tabular}

3.3. Mortality. Overall in-hospital postoperative mortality in the present study was $6.1 \%$ (14 of 230). Figure 1 illustrates

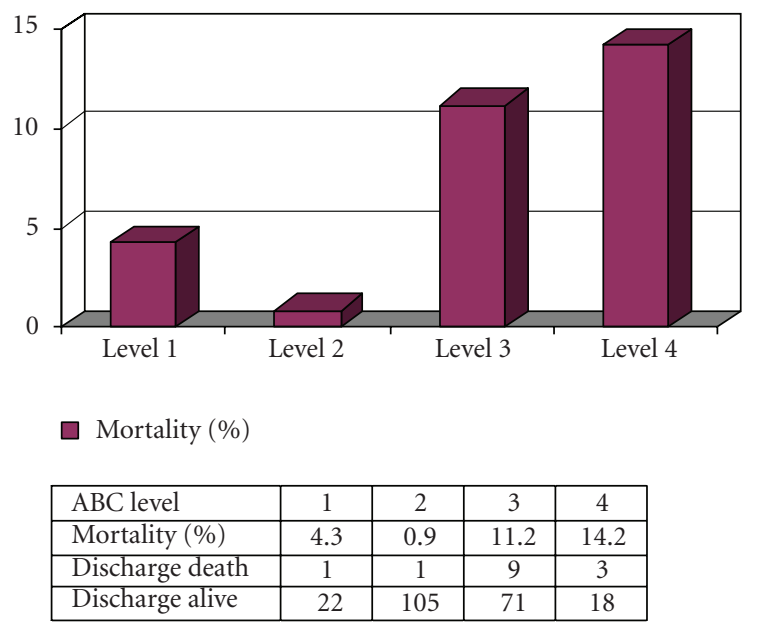

Figure 3: Mortality rate by $\mathrm{ABC}$ level in the present study $(n=$ 230).

the mortality using the RACHS- 1 system, with the mortality increasing significantly between level 2 and levels 3 and $4(P$ value $<.05)$. The area under the ROC curve was 0.78 , with a $95 \%$ confidence interval between 0.669 and 0.897 . Figure 2 shows the mortality, based on the $\mathrm{ABC}$ level, with the highest percentage of mortality at $\mathrm{ABC}$ level 4 (14.2\%). The area under the ROC curve for this $\mathrm{ABC}$ level was 0.74 with a $95 \%$ confidence interval between 0.60 and 0.84 . Mortality rate and the STS-EACTS Mortality categories are also shown in Figure 3. For this method, the highest proportion of mortality cases was in category 3 . The area under the ROC curve was 0.66 with a $95 \%$ confidence interval between 0.53 and 0.81 . Detailed descriptions of death and potential risk variables are summarized in Table 4 .

3.4. Risk Analysis. Potential risk factors of mortality discharge were evaluated by univariate analysis (summarized in Table 5). No mortality discharge occurred with patients at the RACHS-1 level 1 , in contrast to $100 \%$ mortality 
TABLE 2: Surgical procedures in the present study $(n=230)$.

\begin{tabular}{|c|c|}
\hline Procedures & $n(\%)$ \\
\hline VSD patch closure & $70(30.4)$ \\
\hline TOF repair (transannular patch technique) & $37(16.1)$ \\
\hline Systemic to pulmonary shunt & $27(11.8)$ \\
\hline AVC correction & $17(7.5)$ \\
\hline ASD closure & $14(6.1)$ \\
\hline Fontan operation & $10(4.4)$ \\
\hline Rastelli operation (RV-PA conduit) & $8(3.5)$ \\
\hline Glenn operation & $8(3.5)$ \\
\hline Arterial switch operation (ASO) + VSD closure & $5(2.1)$ \\
\hline Pulmonary artery banding (PAB) & $4(1.7)$ \\
\hline Ebstein's repair & $4(1.7)$ \\
\hline PDA ligation & $4(1.7)$ \\
\hline \multicolumn{2}{|l|}{ Coarctation repair (end to end anastomosis) } \\
\hline Coarctectomy + PDA ligation & $4(1.7)$ \\
\hline Coarctectomy + PA banding & $2(0.9)$ \\
\hline Truncus repair & $2(0.9)$ \\
\hline Mitral valve annuloplasty/replacement & $2(0.9)$ \\
\hline Pulmonary valvulotomy & $2(0.9)$ \\
\hline PDA ligation + remove vegetation & $2(0.9)$ \\
\hline Arterial switch operation (ASO) & $2(0.9)$ \\
\hline PAVC repair & $1(0.4)$ \\
\hline Glenn operation + valve repair & $1(0.4)$ \\
\hline Hemifontan operation & $1(0.4)$ \\
\hline Atrial switch operation & $1(0.4)$ \\
\hline Ross operation & $1(0.4)$ \\
\hline $\begin{array}{l}\text { Tricuspid valve repositioning in neonatal Ebstein } \\
\text { anomaly at age }<30 \text { days }\end{array}$ & $1(0.4)$ \\
\hline
\end{tabular}

VSD: ventricular septal defect, ASD: atrial septal defect, PDA: patent ductus arteriosus, AVC: atrioventricular canal, TOF: tetralogy of Fallot, RV: right ventricle, PA: pulmonary artery, ASO: arterial switch operation, and PAVC: partial atrioventricular canal.

discharge of patients with patients at the RACHS-1 level 5 . Consequently, estimation by the logistic regression model could not be assumed to be valid. Therefore, the separation between groups, defined by the RACHS-1 levels, was performed logically by grouping together RACHS-1 levels 13 and levels 4-6. In addition, bypass time and cross clamp time were analyzed by ROC, to determine cutoff values for the study. 84.5 minutes of bypass time (sensitivity $=91 \%$ and specificity $=64 \%$ ) and 59 minutes of cross clamp time (sensitivity $=66 \%$ and specificity $=75 \%$ ) were suitable for separate groups for in-hospital death prediction. Results from the univariate model and a forward stepwise logistic regression model showed a significant increased risk of death associated with the RACHS-1 level 4-6 (OR = 10.0), the ABC level 3-4 (OR = 8.5), the STS-EACTS Mortality Categories
3-5 $(\mathrm{OR}=4.1)$, bypass time $>85$ minutes $(\mathrm{OR}=19.8)$, and cross clamp time $>60$ minutes $(\mathrm{OR}=6.3)$ ( see Table 6$)$.

3.5. Complications and Length of Stay. Table 7 shows the major postoperative complications and morbidities occurring in our cases. The common events were postoperative pyrexia $(43.0 \%)$, redo due to bleeding or tamponade and unstable hemodynamic (9.6\%), pleural effusion including chylothorax $(8.6 \%)$, and cardiac arrhythmia events, which required medical intervention or electrical cardioversion $(8.7 \%)$.

\section{Discussion}

In recent years, the attitude towards quality of health care and the cost of congenital heart surgery has received much attention from the public and is the subject of government coverage scrutiny. The RACHS-1 method was established to analyze the impact of case mix on pediatric cardiac surgical outcomes by Jenkins et al. [11, 12]. In 2006, the STS and EACTS also incorporated the RACHS-1 into their databases [17, 18]. Many institutes in Europe and North America reported use of the RACHS-1 with comparisons of inter-institutional performance [10, 13, 17, 19-21]. Some authors also validated RACHS-1 stratification for use with a subset of pediatric cardiac surgeries, by considering the area under the ROC curve $(0.75-0.86)$ [21, 22]. Meanwhile, Lacour-Gayet et al. [14, 15] introduced the Aristotle basic complexity score (ABC score) to predict surgical mortality. The complexity tool allocates a basic score (range from 1.5 to 5) and a level (range from 1 to 4 ) for each operation. Subsequently, the authors developed the Aristotle Comprehensive complexity score for a more complex stratification, based on procedure-dependent factors such as anatomical factors, age at procedure, and patient-adjusted factors such as extracardiac factors and general factors [14, 23]. The novel method has been accepted for use in several studies, with its validity (by c statistic) at 0.74 to $0.8[16,17,23]$. The most recent complexity stratification tool, published in 2009 , is the STS-EACTS congenital heart surgery mortality score. It uses additional factors such as age, weight, and preoperative LOS and was shown to have a high validity (by c statistic) of $0.816[16,17]$. These stratification tools are helpful methods for analyzing the case mix in pediatric cardiac surgeries.

To date, few reports have mentioned any evaluation of pediatric cardiac outcomes from developing countries $[2,3,24,25]$. Vélez et al., from Colombia, indicated that patients with RACHS-1 levels 1 to 4 had mortality rates of $0.7 \%, 7.2 \%, 20.7 \%$, and $33.8 \%$, respectively [3]. Also, in Guatemala, a study demonstrated improvement in congenital heart surgery (from 1997 to 2004) using the RACHS1 stratification [2]. Regarding a limitation of resource and prior data, the authors attempted to survey a surgical performance in a single center to provide fundamental information for longitudinal study and a multi-institutional report. The RACHS-1, ABC, and STS-EACTS mortality scoring systems appear to be sensible tools, with simple language and interpretation. Nevertheless, each system is recognized 
TABLE 3: Distribution of cases by the RACHS-1 risk categories, the Aristotle basic complexity levels, and STS-EACTS mortality categories.

\begin{tabular}{|c|c|c|c|c|c|c|c|c|c|}
\hline $\begin{array}{l}\text { RACHS-1 } \\
\text { level }\end{array}$ & $N(\%)$ & ABC level & ABC score & $\begin{array}{l}\text { Mean ABC } \\
\text { score } \pm \text { SD }\end{array}$ & $N(\%)$ & $\begin{array}{c}\text { STS-EACTS } \\
\text { category }\end{array}$ & $\begin{array}{c}\text { STS-EACTS } \\
\text { score }\end{array}$ & $\begin{array}{c}\text { Mean } \\
\text { STS-EACTS } \\
\text { score } \pm \text { SD }\end{array}$ & $N(\%)$ \\
\hline I & $22(9.6)$ & I & $1.5-5.9$ & $3.2 \pm 6.6$ & $23(10)$ & I & $0.1-0.3$ & $0.19 \pm 0.05$ & $90(39.1)$ \\
\hline II & $118(51.3)$ & II & $6-7.9$ & $6.1 \pm 0.3$ & $106(46.1)$ & II & $0.4-0.7$ & $0.51 \pm 0.06$ & $64(27.8)$ \\
\hline III & $81(35.2)$ & II & $8-9.9$ & $8.4 \pm 0.6$ & $80(34.8)$ & III & $0.8-1.2$ & $0.84 \pm 0.09$ & $28(12.2)$ \\
\hline IV & $8(3.5)$ & IV & $10-15$ & $10.3 \pm 0.5$ & $21(9.1)$ & IV & $1.3-2.6$ & $1.61 \pm 0.23$ & 48 (20.9) \\
\hline V & $1(0.4)$ & & & & & $\mathrm{V}$ & $2.7-5$ & - & $0(0)$ \\
\hline VI & $0(0)$ & & & & & & & & \\
\hline Total & 230 & & & $7.1 \pm 1.9$ & 230 & & & $0.65 \pm 0.54$ & 230 \\
\hline
\end{tabular}

TABLE 4: Summary of discharge mortality cases.

\begin{tabular}{|c|c|c|c|c|c|c|c|c|c|}
\hline No. & $\begin{array}{l}\text { Age } \\
\text { (years) }\end{array}$ & Sex & Diagnosis & Surgical type & $\begin{array}{l}\mathrm{CPB} \\
\text { time } \\
(\mathrm{min})\end{array}$ & $\begin{array}{l}\text { AoX } \\
\text { time } \\
(\mathrm{min})\end{array}$ & $\begin{array}{l}\text { Death } \\
\text { at PO } \\
\text { day }\end{array}$ & $\begin{array}{l}\text { RACHS-1 } \\
\text { level }\end{array}$ & Cause \\
\hline 1 & 1.23 & Male & Primum ASD & Total repair & 101 & 68 & 7 & II & Cardiac tamponade \\
\hline 2 & 10 & Female & UVH & Fontan & 200 & 49 & 1 & III & Low output, VT, and \\
\hline 3 & 11.9 & Male & TOF & Total repair & 104 & 70 & 47 & II & $\begin{array}{c}\text { P. auruginosa } \\
\text { pneumonia, MRSA } \\
\text { Sepsis, IE, and } \\
\text { diaphragm paralysis }\end{array}$ \\
\hline 4 & 3.9 & Female & $\begin{array}{c}\text { Unbalance AVC } \\
\text { and PS }\end{array}$ & Fontan & 240 & 0 & 0 & III & Low output \\
\hline 5 & 1.97 & Male & UVH and PS & Central shunt & 94 & 0 & 1 & III & Low output \\
\hline 6 & 0.36 & Female & CAVC & Total repair & 99 & 76 & 87 & III & $\begin{array}{c}\text { A. buamnii } \\
\text { pneumonia, } \\
\text { P. auruginosa sepsis }\end{array}$ \\
\hline 7 & 4.74 & Female & UVH, PS & Fontan & 86 & 0 & 2 & III & Low output \\
\hline 8 & 0.51 & Male & CAVC & Total repair & 90 & 70 & 45 & III & $\begin{array}{l}\text { Sepsis, DIC, and } \\
\text { residual shunt }\end{array}$ \\
\hline 9 & 0.7 & Female & CAVC & Total repair & 160 & 60 & 2 & III & PHT crisis \\
\hline 10 & 0.86 & Male & CAVC & Total repair & 174 & 127 & 40 & III & Candida sepsis \\
\hline 11 & 0.04 & Male & $\begin{array}{c}\text { Ebstein anomaly } \\
\text { and PS }\end{array}$ & $\begin{array}{l}\text { Pulmonic } \\
\text { valvluotomy, } \\
\text { TVR repair }\end{array}$ & 43 & 0 & 1 & $\mathrm{~V}$ & Low output \\
\hline 12 & 0.5 & Male & CAVC & Total repair & 145 & 77 & 1 & III & Low output, and VT \\
\hline 13 & 2.24 & Male & TGA, VSD & $\begin{array}{l}\text { ASO and VSD } \\
\text { closure }\end{array}$ & 134 & 70 & 2 & IV & Low output \\
\hline 14 & 0.13 & Female & $\begin{array}{l}\text { Truncus } \\
\text { arteriosus }\end{array}$ & Total repair & 156 & 68 & 0 & IV & Low output \\
\hline
\end{tabular}

CPB: cardiopulmonary bypass, AoX: aortic clamp, ASD: atrial septal defect, UVH: univentricular heart, TOF: tetralogy of Fallot, AVC: atrioventricular canal, CAVC: complete atrioventricular repair, PS: pulmonary stenosis, TGA: transposition of great arteries, PHT crisis: pulmonary hypertensive crisis, VT: ventricular tachycardia, DIC: disseminated intravascular coagulopathy.

for limitations such as not having classifications for heart transplantation, fenestrated ASD closure, fenestrated VSD closure, truncal valve annuloplasty, and one and a half repair in the RACHS-1 method [8]. For our retrospective database, complete patients' clinical factors were not available for applying the Aristotle comprehensive complexity score, or for applying the adjusted patient-level risk level in the STSEACTS scoring system. As a result, we used all classifications to stratify the clinical database to determine cross-sectional mortality.
In the present study, postoperative in-hospital mortality was $6.1 \%$, with increasing mortality rates at the higher levels of the RACHS- 1 and the ABC. Nevertheless, only one patient was categorized at the RACHS- 1 level 5, and no patients were at RACHS-1 level 6. Also, the Norwood procedure was not performed during the one-year study. The mean $\mathrm{ABC}$ score was $7.1 \pm 1.9$, which represents a complexity between ABC levels 2 and 3. Likewise, the mean STSEACTS mortality score placed our complexity of procedures into categories 2-3. These scores imply a procedural-based 
TABLE 5: Univariate analysis of independent variables in the present study $(n=230)$.

\begin{tabular}{|c|c|c|c|}
\hline Variables & Alive discharge $n(\%)($ total $=216)$ & Mortality discharge $n(\%)($ total $=14)$ & $P$ value \\
\hline \multicolumn{4}{|l|}{ Sex; $n(\%)$} \\
\hline Male & $119(94.4 \%)$ & $7(5.6 \%)$ & .925 \\
\hline Female & $97(93.3 \%)$ & $7(6.7 \%)$ & \\
\hline Age (years); median (range) & $3.18(0.03-15.29)$ & $1.05(0.04-11.93)$ & .069 \\
\hline \multicolumn{4}{|l|}{ RACHS-1 level; $n(\%)$} \\
\hline 1 & $22(100 \%)$ & $0(0 \%)$ & $<.001$ \\
\hline 2 & $116(98.3 \%)$ & $2(1.7 \%)$ & \\
\hline 3 & $72(88.9 \%)$ & $9(11.1 \%)$ & \\
\hline 4 & $6(75 \%)$ & $2(25 \%)$ & \\
\hline 5 & $0(0 \%)$ & $1(100 \%)$ & \\
\hline 6 & - & - & \\
\hline ABC level; $n(\%)$ & & & $<.001$ \\
\hline 1 & $22(95.7 \%)$ & $1(4.3 \%)$ & \\
\hline 2 & $105(99.1 \%)$ & $1(0.9 \%)$ & \\
\hline 3 & $71(88.8 \%)$ & $9(11.2 \%)$ & \\
\hline 4 & $18(85.8 \%)$ & $3(14.2 \%)$ & \\
\hline STS-EACTS mortality categories; $n(\%)$ & & & .01 \\
\hline 1 & $89(98.9)$ & $1(1.1)$ & \\
\hline 2 & $60(93.8)$ & $4(6.2)$ & \\
\hline 3 & $23(82.2)$ & $5(17.8)$ & \\
\hline 4 & $44(91.7)$ & $4(8.3)$ & \\
\hline 5 & - & - & \\
\hline Bypass time (min.); median (range) & $71(0-289)$ & $119(43-240)$ & .002 \\
\hline Cross clamp time (min); median (range) & $37(0-148)$ & $69(0-127)$ & .019 \\
\hline
\end{tabular}

TABLE 6: Risk of death estimated by univariate and multivariate analysis using categorical data in the present study.

\begin{tabular}{|c|c|c|c|c|}
\hline Variables & $\begin{array}{l}\text { Alive discharge } \\
\quad(n=216)\end{array}$ & $\begin{array}{l}\text { Mortality discharge } \\
\quad(n=14)\end{array}$ & $\begin{array}{c}\text { Crude odds ratio } \\
(95 \% \mathrm{CI})\end{array}$ & $\begin{array}{c}\text { Adjusted odds ratio } \\
(95 \% \mathrm{CI})\end{array}$ \\
\hline \multicolumn{5}{|c|}{ Age at operation; $n(\%)$} \\
\hline$<30$ days & $7(87.5)$ & $1(12.5)$ & 1 & \\
\hline$>30$ days & $209(94.1)$ & $13(5.9)$ & $0.4(0.1-3.8)$ & \\
\hline \multicolumn{5}{|c|}{ RACHS-1 level; $n(\%)$} \\
\hline $1-3$ & $210(95.0)$ & $11(5.0)$ & 1 & 1 \\
\hline $4-6$ & $6(66.7)$ & $3(33.3)$ & $9.5(2.1-43.3)$ & $10.0(1.6-62.0)^{*}$ \\
\hline \multicolumn{5}{|c|}{ ABC level; $n(\%)$} \\
\hline $1-2$ & $127(98.5)$ & $2(1.5)$ & 1 & \\
\hline $3-4$ & $89(88.1)$ & $12(11.9)$ & $8.5(1.9-39.1)$ & \\
\hline \multicolumn{5}{|c|}{$\begin{array}{l}\text { STS-EACTS mortality } \\
\text { category }\end{array}$} \\
\hline $1-2$ & 149 & 5 & 1 & \\
\hline $3-5$ & 67 & 9 & $4.1(1.2-12.3)$ & \\
\hline \multicolumn{5}{|c|}{ Bypass time (min.); $n(\%)$} \\
\hline$\leq 85$ & $125(99.2)$ & $1(0.8)$ & 1 & \\
\hline$>85$ & $82(86.3)$ & $13(13.7)$ & $19.8(2.5-154.4)$ & \\
\hline \multicolumn{5}{|c|}{$\begin{array}{l}\text { Cross clamp time (min.); } \\
n(\%)\end{array}$} \\
\hline$\leq 60$ & $154(97.5)$ & $4(2.5)$ & 1 & \\
\hline$>60$ & $49(86.0)$ & $8(14.0)$ & $6.3(1.8-21.8)$ & \\
\hline
\end{tabular}

${ }^{*} P$ value $=.013,{ }^{* *} P$-value $=.001$. 
TABLE 7: Major postoperative complications and morbidities $(n=230)$.

\begin{tabular}{lc}
\hline Variables & $n(\%)$ \\
\hline Postoperative pyrexia & $99(43.0)$ \\
Bleeding, cardiac tamponade, and unstable & $22(9.6)$ \\
hemodynamic requiring reoperation & $20(8.6)$ \\
Pleural effusion and chylothorax & $20(8.7)$ \\
Serious cardiac arrhythmia (total events) & $4(2.3)$ \\
$\quad$ (i) Junctional ectopic tachycardia & $2(0.8)$ \\
(ii) Autonomic ectopic tachycardia & $2(0.8)$ \\
(iii) Supraventricular tachycardia & $3(2.3)$ \\
$\quad$ (iv) Ventricular tachycardia & $1(0.4)$ \\
$\quad$ v) Ventricular fibrillation & $1(1.3)$ \\
(vi) Junctional rhythm (required temporary pacing) & $6(2.8)$ \\
$\quad$ (vii) Complete heart block & $12(5.2)$ \\
Required reintubation & $6(2.6)$ \\
Renal failure required peritoneal dialysis & $4(1.7)$ \\
Pneumothorax (needed more ICD) & $1(0.5)$ \\
Wound infection and mediastinitis & $0(0)$ \\
Neurological deficit & $0(0)$ \\
Anticoagulation complication &
\end{tabular}

ICD: intercostal drainage, CPR: cardiopulmonary resuscitation.

level of complexity in the institute, which would be useful information for a longitudinal study.

Overall, the present study shows that three scoring systems can be applied to a medium volume hospital. The areas under the ROC curves for the RACHS- 1 and ABC systems, for predicting in-hospital mortality, are impressive, 0.78 and 0.74 , respectively. These values are close to the results from other studies [13,16, 18, 20-22]. Interestingly, the mortality rate distributed by the STS-EACTS mortality categories looks a bit different from those of the RACHS-1 or ABC score. In the STS-EACTS mortality categories, the highest mortality percentage was found at mortality level 3 $(17.8 \%)$, followed by level 4 (8.3\%), and then level $2(6.2 \%)$. As a possible explanation, some of the procedures that are classified in the STS-EACTS mortality category 4, such as systemic to pulmonary artery shunt, have been performed commonly in the institute with a low mortality rate. The atrioventricular canal repair, in contrast, which is categorized in the STS-EACTS category 3, shows a high mortality rate. For a small sample size, the proportion of mortality is skewed considerably toward the STS-EACTS category 3 . As a result, the area under the ROC curve for the STS-EACTS system was 0.66. By comparing our results to those of the largest database from the STS and EACTS congenital register $[16,17]$, the performance at our center has a much higher mortality, especially for complex procedures. Accordingly, the performance of congenital heart surgery at the institute needs to be improved to achieve a standard of quality as shown in Figure 4.

Using a stepwise logistic model and a predictive model, we found that high RACHS-1 levels (levels 4-6), high ABC levels (levels 3-4), high STS-EACTS mortality categories

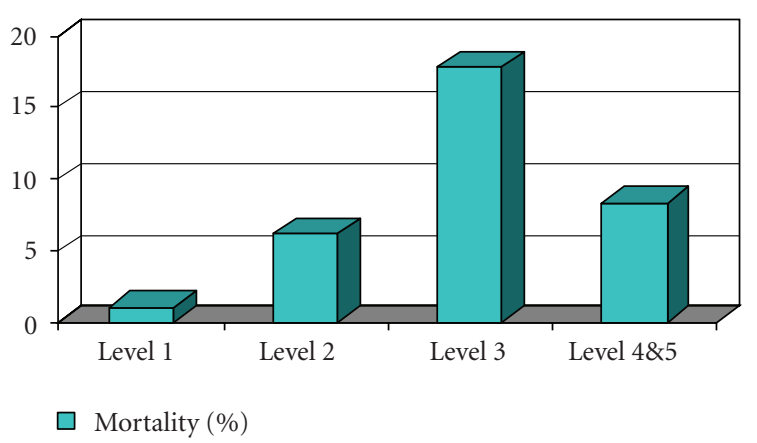

\begin{tabular}{|l|c|c|c|c|}
\hline $\begin{array}{l}\text { The STS-EACTS mortality } \\
\text { catalog }\end{array}$ & 1 & 2 & 3 & $4 \& 5$ \\
\hline Mortality (\%) & 1.1 & 6.2 & 17.8 & 8.3 \\
\hline Discharge death & 1 & 4 & 5 & 4 \\
\hline Discharge alive & 89 & 60 & 23 & 44 \\
\hline
\end{tabular}

FIGURE 4: Mortality rate by STS-EACTS mortality categories in the present study $(n=230)$.

(categories 3-5), bypass time $>85$ minutes, and cross clamp time $>60$ minutes were significantly associated with high mortality $(\mathrm{OR}=10.0,8.5,4.1,19.8$, and 6.3 , resp.). The bypass times and aortic cross clamp time significantly affect the mortality since they generally reflect the difficulty of procedures and the complexity of diseases. After reviewing every death case, we also found that atrioventricular canal repair has the highest risk of surgery (mortality discharge of $35 \%$ ). The causes of death included sepsis, pulmonary hypertensive crisis, low output, and cardiac arrhythmia.

In the present study, the most common complications were postoperative fever $(43 \%)$, and bleeding tamponade, caused by unstable hemodynamic requiring reoperation (9.6\%). Other morbidities appeared to be similar to those reported by other authors $[1,2,6,26]$. For a meaningful clinical correlation, we explored cases where the patient developed fever within 10 days after the operation. Definite etiologies of pyrexia were identified in only $63.3 \%$ of the patients. The three most common causes of fever were pneumonia $(29.6 \%)$, postpericardiotomy syndrome (23.5\%), and bacteremia (6.1\%). Postoperative fever itself does not directly predict a mortality $(\mathrm{OR}=0.9,95 \% \mathrm{CI}$ $=0.3-2.9)$. By contrast, the risk mortality of the patients with postoperative major infections was 2.6 times that of the non-infectious group ( $95 \% \mathrm{CI}=1.8-9.5)$. In terms of other complications, significant associations were seen between mortality and bleeding tamponade caused by unstable hemodynamic requiring reoperation $(\mathrm{OR}=11,95 \% \mathrm{CI}=$ 3.4-34.0), reintubation incidence $(\mathrm{OR}=10.4,95 \% \mathrm{CI}=2.4-$ $40)$, and renal failure requiring dialysis $(\mathrm{OR}=8.1,95 \% \mathrm{CI}$ $=1.8-35)$, and cardiac arrhythmia $(\mathrm{OR}=3.4,95 \% \mathrm{CI}=$ 1-15.7). These complications need to be recognized early during postoperative care.

Interestingly, the high $\mathrm{ABC}$ levels (level 3-4) are associated with many complications: postoperative cardiac arrhythmia $(\mathrm{OR}=3.3,95 \% \mathrm{CI}=1.1-9.8)$, postoperative pleural effusion $(\mathrm{OR}=3.3,95 \% \mathrm{CI}=1.3-9.5)$, reintubation 
incidence $(\mathrm{OR}=6.9,95 \% \mathrm{CI}=1.4-32)$, renal failure requiring dialysis $(P$ value $<.001)$, while the high RACHS-1 levels (levels 4-6) were highly associated with postoperative cardiac arrhythmia $(\mathrm{OR}=7.6,95 \% \mathrm{CI}=1.7-32.7)$. Nevertheless, in the present study, none of the three stratification tools were able to predict common complications, for instance, postoperative fever and bleeding tamponade caused by unstable hemodynamic requiring reoperation. With a larger sample size and a longer period of study, further implications and predictions of postoperative complications could be obtained from the risk stratification.

\section{Limitations}

(1) The patient population in the present study was rather small. The sample size was adequate for estimating only a two-sided $95 \%$ confidence interval (alpha level of 0.05 ) for a prevalence of mortality of $15 \pm 5 \%$. After categorizing patients into the risk models, the statistical power was reduced though some variables showed a strong association with the mortality discharge.

(2) Since this was a retrospective study, selection bias is inevitable. Some variables, such as noncardiac anomalies, genetic syndromes diagnosed by characteristics, and socioeconomic status could not be traced.

(3) This is the first time that the RACHS-1 classification and ABC scoring system has been applied to our population. The experts and pediatric cardiologists of our institutions have to scrutinize and explore the raw data before interpretation.

(4) In the present study, the exclusion criteria was limited by age (between $0-15$ years of age), which could skew the results. We excluded preterm, which represents a high-risk group in the ABC and STS-EACTS scoring systems, to reduce conflicts from mortality due to unrelated factors. In addition, adolescents (15-18 years old), who had been admitted to adult care units, were excluded by the unique infrastructure of the hospital. Since this is a preliminary report, to provide an initial measurement of the surgical performance at the institute, we intend to adjust the criteria in the next longitudinal study.

(5) An aggregated database over a longer time may suggest trends that can be used to improve the subsets. Moreover, the interinstitutional case-mix will reveal overall outcomes for nation-wide improvements in quality of care for these patients.

\section{Conclusions}

The RACHS-1, ABC, and STS-EACTS mortality scoring systems are useful tools for assessing mortality discharge in a medium volume cardiac center in Thailand. The overall postoperative in-hospital mortality rate was found to be $6.1 \%$. The important risk factors for postoperative mortality were the high RACHS-1 level, high ABC level, high STSEACTS mortality categories, and prolonged bypass time. The most common complications were postoperative fever, and bleeding tamponade causing unstable hemodynamic requiring reoperation, which are not well predicted by the risk complexity tools.

\section{Acknowledgments}

The authors wish to thank Dr. Marion Tipple (Children's Heart Centre, British Columbia Children's Hospital) and Glen Wheeler for proofreading and editing this paper. They also thank to Dr. Pansak Laksanabunsong (Siriraj Hospital), Dr. Wanchai Wongkornrat (Siriraj Hospital), and all administrators of pediatric cardiology as well as cardiovascular thoracic surgery for their assistance on the database.

\section{References}

[1] S. L. Rohde, M. Matebele, P. Pohlner, D. Radford, D. Wall, and J. F. Fraser, "Excellent cardiac surgical outcomes in paediatric indigenous patients, but follow-up difficulties," Heart Lung and Circulation, vol. 19, no. 9, pp. 517-522, 2010.

[2] L. A. Larrazabal, K. J. Jenkins, K. Gauvreau et al., "Improvement in congenital heart surgery in a developing country: the Guatemalan experience," Circulation, vol. 116, no. 17, pp. 1882-1887, 2007.

[3] J. Vélez, N. Sandoval, E. Cadavid, and J. Zapata, "Cooperative study of operatory mortality in the correction of congenital cardiopathies in Colombia," Revista Colombiana de Cardiologia, vol. 11, pp. 397-400, 2005.

[4] A. F. Rossi and D. Khan, "Point of care testing: improving pediatric outcomes," Clinical Biochemistry, vol. 37, no. 6, pp. 456-461, 2004.

[5] K. F. Welke, B. S. Diggs, T. Karamlou, and R. M. Ungerleider, "Comparison of pediatric cardiac surgical mortality rates from national administrative data to contemporary clinical standards," Annals of Thoracic Surgery, vol. 87, no. 1, pp. 216223, 2009.

[6] R.-K. R. Chang, S. Rodriguez, M. Lee, and T. S. Klitzner, "Risk factors for deaths occurring within 30 days and 1 year after hospital discharge for cardiac surgery among pediatric patients," American Heart Journal, vol. 152, no. 2, pp. 386-393, 2006.

[7] M. J. Silka, B. G. Hardy, V. D. Menashe, and C. D. Morris, "A population-based prospective evaluation of risk of sudden cardiac death after operation for common congenital heart defects," Journal of the American College of Cardiology, vol. 32, no. 1, pp. 245-251, 1998.

[8] K. F. Welke, B. S. Diggs, and T. Karamlou, "Chance, bias, and confounding: Threats to valid measurement of quality in the context of pediatric cardiac surgery," Seminars in Thoracic and Cardiovascular Surgery: Pediatric Cardiac Surgery Annual, vol. 13, no. 1, pp. 79-83, 2010.

[9] V. T. Tsang, K. L. Brown, M. J. Synnergren et al., "Monitoring risk-adjusted outcomes in congenital heart surgery: does the appropriateness of a risk model change with time?" Annals of Thoracic Surgery, vol. 87, no. 2, pp. 584-587, 2009.

[10] O. O. Al-Radi, F. E. Harrell Jr., C. A. Caldarone et al., "Case complexity scores in congenital heart surgery: a comparative study of the Aristotle Basic Complexity score and the Risk 
Adjustment in Congenital Heart Surgery (RACHS-1) system," Journal of Thoracic and Cardiovascular Surgery, vol. 133, no. 4, pp. 865-875, 2007.

[11] K. J. Jenkins, K. Gauvreau, J. W. Newburger, T. L. Spray, J. H. Moller, and L. I. Iezzoni, "Consensus-based method for risk adjustment for surgery for congenital heart disease," Journal of Thoracic and Cardiovascular Surgery, vol. 123, no. 1, pp. 110118, 2002.

[12] K. J. Jenkins, "Risk adjustment for congenital heart surgery: the RACHS-1 method," Pediatric Cardiac Surgery Annual, vol. 7, pp. 180-184, 2004.

[13] N. Kang, T. Cole, V. Tsang, M. Elliott, and M. De Leval, "Risk stratification in paediatric open-heart surgery," European Journal of Cardio-thoracic Surgery, vol. 26, no. 1, pp. 3-11, 2004.

[14] F. Lacour-Gayet, D. Clarke, J. Jacobs et al., "The Aristotle score for congenital heart surgery," Pediatric Cardiac Surgery Annual, vol. 7, pp. 185-191, 2004.

[15] F. Lacour-Gayet, D. Clarke, J. Jacobs et al., "The Aristotle score: a complexity-adjusted method to evaluate surgical results," European Journal of Cardio-thoracic Surgery, vol. 25, no. 6, pp. 911-924, 2004.

[16] S. M. O’Brien, D. R. Clarke, J. P. Jacobs et al., "An empirically based tool for analyzing mortality associated with congenital heart surgery," Journal of Thoracic and Cardiovascular Surgery, vol. 138, no. 5, pp. 1139-1153, 2009.

[17] J. P. Jacobs, M. L. Jacobs, F. G. Lacour-Gayet et al., "Stratification of complexity improves the utility and accuracy of outcomes analysis in a Multi-Institutional Congenital Heart Surgery Database: application of the Risk Adjustment in Congenital Heart Surgery (RACHS-1) and Aristotle Systems in the Society of Thoracic Surgeons (STS) Congenital Heart Surgery Database," Pediatric cardiology, vol. 30, no. 8, pp. 1117-1130, 2009.

[18] K. F. Welke, I. Shen, and R. M. Ungerleider, "Current assessment of mortality rates in congenital cardiac surgery," Annals of Thoracic Surgery, vol. 82, no. 1, pp. 164-171, 2006.

[19] L. G. Bazzani and J. P. Marcin, "Case volume and mortality in pediatric cardiac surgery patients in California, 1998-2003," Circulation, vol. 115, no. 20, pp. 2652-2659, 2007.

[20] M. L. Jacobs, J. P. Jacobs, K. J. Jenkins, K. Gauvreau, D. R. Clarke, and F. Lacour-Gayet, "Stratification of complexity: the Risk Adjustment for Congenital Heart Surgery-1 method and the Aristotle Complexity Score-past, present, and future," Cardiology in the Young, vol. 18, pp. 163-168, 2008.

[21] D. Boethig, K. J. Jenkins, H. Hecker, W. R. Thies, and T. Breymann, "The RACHS-1 risk categories reflect mortality and length of hospital stay in a large German pediatric cardiac surgery population," European Journal of Cardiothoracic Surgery, vol. 26, no. 1, pp. 12-17, 2004.

[22] S. H. Larsen, J. Pedersen, J. Jacobsen, S. P. Johnsen, O. K. Hansen, and V. Hjortdal, "The RACHS-1 risk categories reflect mortality and length of stay in a Danish population of children operated for congenital heart disease," European Journal of Cardio-thoracic Surgery, vol. 28, no. 6, pp. 877-881, 2005.

[23] S. M. O'Brien, J. P. Jacobs, D. R. Clarke et al., "Accuracy of the aristotle basic complexity score for classifying the mortality and morbidity potential of congenital heart surgery operations," Annals of Thoracic Surgery, vol. 84, no. 6, pp. 2027-2037, 2007.

[24] A. Saxena, "Congenital cardiac surgery in the less privileged regions of the world," Expert Review of Cardiovascular Ther$a p y$, vol. 7, no. 12, pp. 1621-1629, 2009.
[25] M. N. Awori and S. W. O. Ogendo, "RACHS-1 System in risk stratification for congenital heart disease surgery outcome," East African Medical Journal, vol. 85, no. 1, pp. 36-38, 2008.

[26] J. R. Leon-Wyss, A. Veshti, O. Veras et al., "Pediatric cardiac surgery: a challenge and outcome analysis of the Guatemala effort," Seminars in Thoracic and Cardiovascular Surgery: Pediatric Cardiac Surgery Annual, vol. 12, no. 1, pp. 8-11, 2009. 


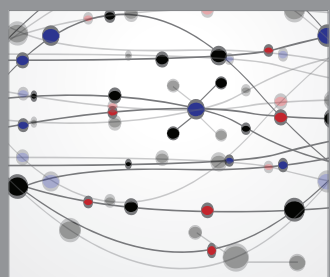

The Scientific World Journal
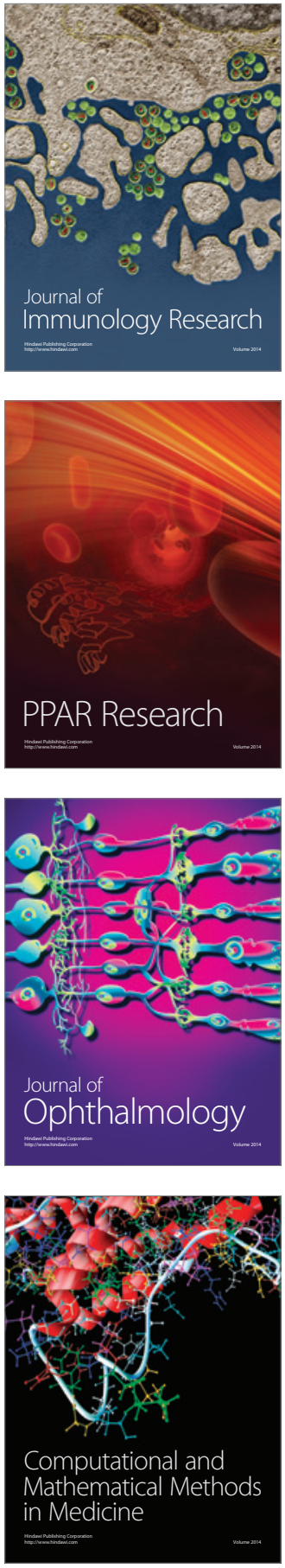

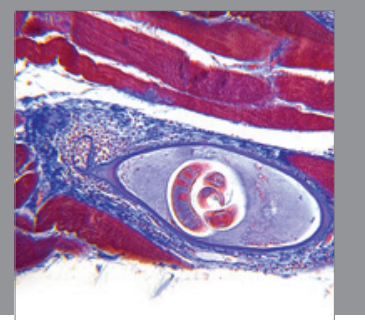

Gastroenterology

Research and Practice
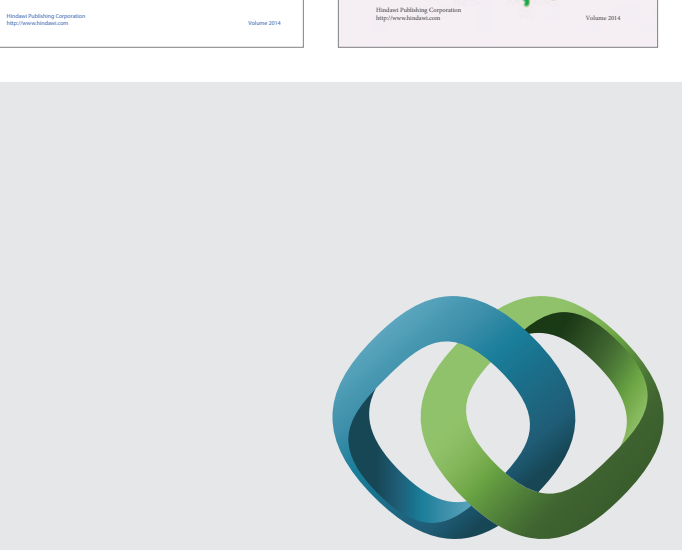

\section{Hindawi}

Submit your manuscripts at

http://www.hindawi.com
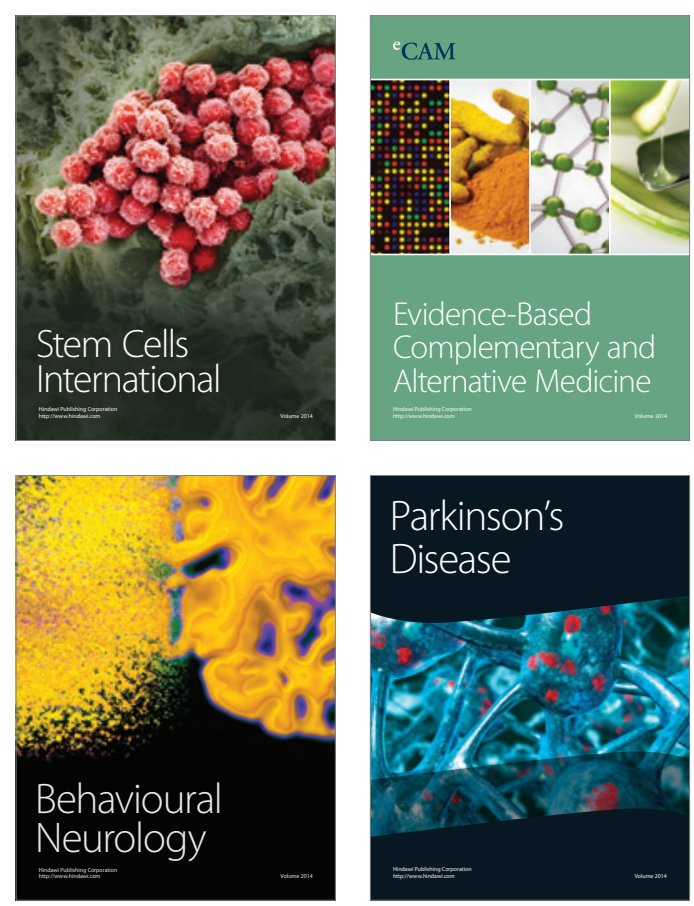

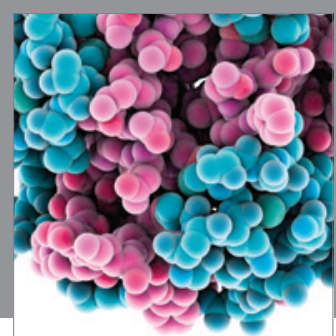

Journal of
Diabetes Research

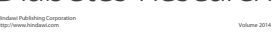

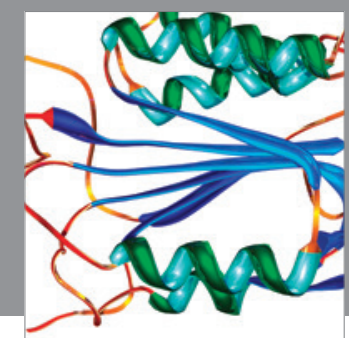

Disease Markers
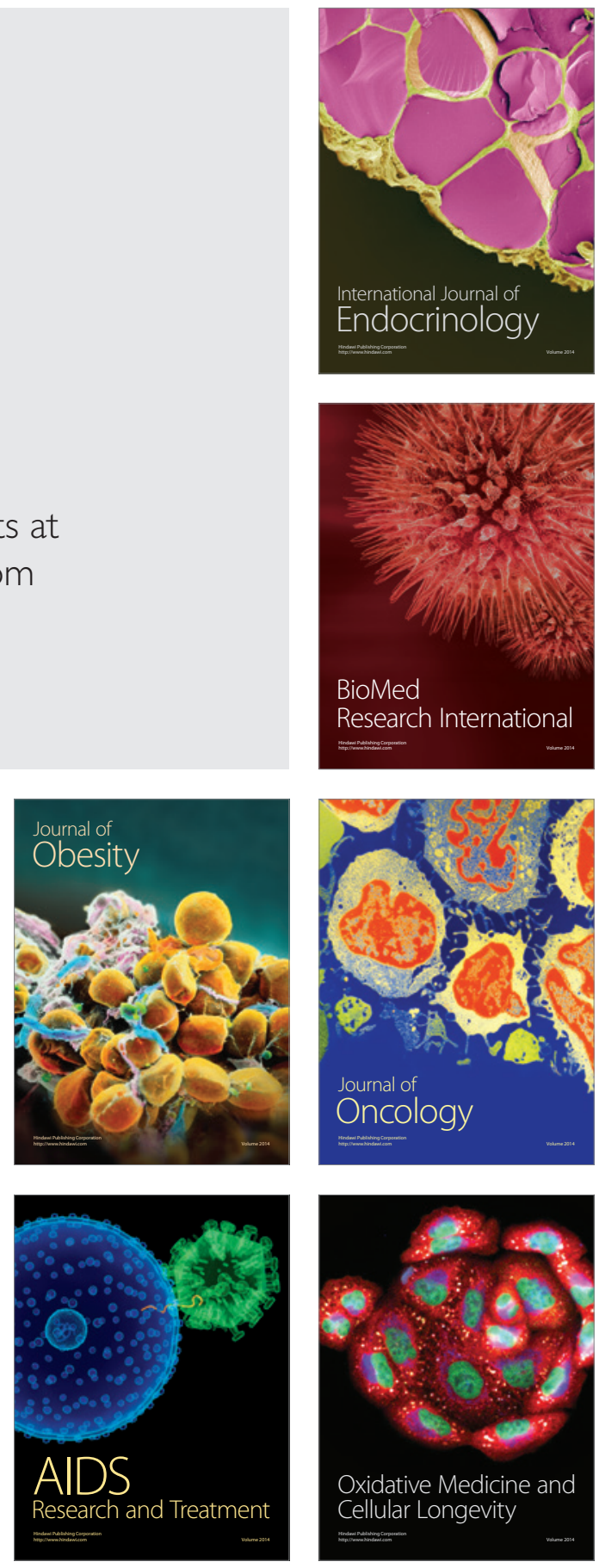